\title{
Antagonism by Sterols of the Action of Amphotericin and Filipin on the Release of Potassium Ions from Candida albicans and Mycoplasma mycoides subsp. capri
}

\author{
By D. B. ARCHER AND E. F. GALE \\ Sub-Department of Chemical Microbiology, Department of Biochemistry, \\ The University, Cambridge $C B 2 \mathrm{I} Q W$
}

(Received I4 April I975)

Polyene antibiotics alter the permeability of the plasma membranes of eukaryotic cells by interacting with sterols. The change in permeability can be monitored by measuring the rate of leakage of potassium ions from sensitive cells (Gale, 1974). Mouse LS cells have been shown to be less sensitive to the action of amphotericin methyl ester (AME) and more sensitive to filipin (FIL) than Candida albicans (Gale, 1973, 1974). The suggestion was made that this difference in sensitivity is based upon the different sterols in the membranes of the two organisms, cholesterol being the main sterol in mouse cell membranes, and ergosterol the main sterol of Candida plasma membranes (Marriott, 1975). When sterols were added together with AME to suspensions of $C$. albicans, ergosterol was found to be more effective than cholesterol in reducing the action of the antibiotic, suggesting that ergosterol has a higher affinity than cholesterol for AME (Gale, 1974; Gale et al. 1975). A similar conclusion was reached by Nozawa et al. (1974) after comparing the effects of amphotericin B on the ultrastructure of fungal membranes, containing ergosterol, with those reported by Verleij et al. (1973) on cholesterol-containing membranes of erythrocytes or Acholeplasma laidlawii. The present communication extends the observations made by the use of $\mathrm{K}^{+}$release measurements on C. albicans, and on Mycoplasma mycoides subsp. capri, grown in the presence of either ergosterol or cholesterol.

The release of $\mathrm{K}^{+}$from $C$. albicans suspensions has been followed by the use of a $\mathrm{K}^{+}$sensitive electrode (Gale, I974). The addition of AME or FIL is followed by a progressively increasing rate of $\mathrm{K}^{+}$leakage, and a standard rate (s.r.) of release has been defined as I $\mathrm{nmol} \mathrm{K} / \mathrm{min} / \mathrm{mg}$ dry wt cells over the rate of release in the absence of antibiotic. In the present experiments, the concentration (s.r.c.) of antibiotic required to induce the s.r. of release in a given time (6 to $10 \mathrm{~min}$ ) at $20{ }^{\circ} \mathrm{C}$ was first determined. Mixtures of sterol and polyene were made up in ethanol in the proportions described below and, in each case, an amount of mixture containing sufficient polyene was added to the cell suspensions to give this final concentration (s.r.c.) in the electrode vessel; the effect of the sterol was then assessed by the increase in time required to reach the s.r. of $\mathrm{K}^{+}$release. Controls of ethanol alone were carried out in all cases. All quantities below are expressed in terms of the active component.

Mycoplasma mycoides is sterol-requiring and sterols present in the growth medium are incorporated into the plasma membrane without alteration; the effect of the growth medium on the lipid composition of $M$. mycoides subsp. capri strain PG3 has been described by Archer (1975). The release of $\mathrm{K}^{+}$from suspensions of Mycoplasma has been studied as for C. albicans except that the organisms were suspended in $0.05 \mathrm{M}$-tris- $\mathrm{HCl}$ buffer $\mathrm{pH} 8.0$ containing $0.125 \mathrm{M}$-sucrose (Archer, I975). AME and FIL induced a constant rate of $\mathrm{K}^{+}$ leakage; the rate varied with antibiotic concentration, but was not time-dependent as with 

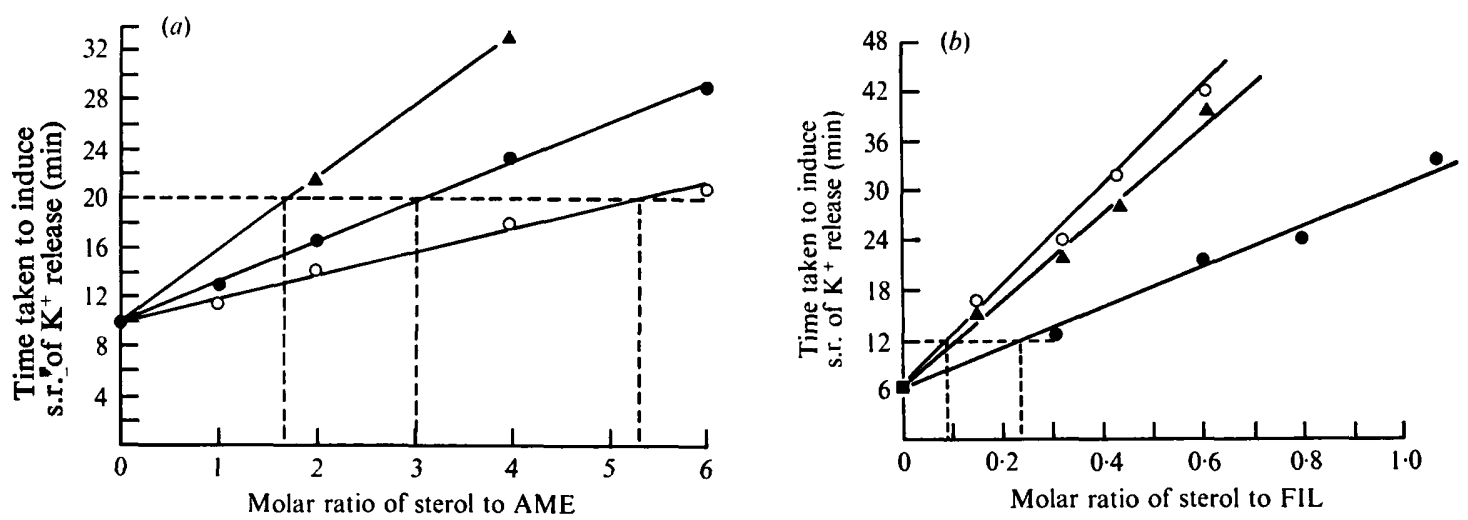

Fig. I. Release of $\mathrm{K}^{+}$from $C$. albicans: antagonism of the action of (a) AME and (b) FIL by sterols. The preparation of Candida suspensions and assay of $\mathrm{K}^{+}$release were as described by Gale (1974). Sterol and polyene mixtures in the proportions shown were made up in ethanol. The s.r.c. of AME required to induce the s.r. of $\mathrm{K}^{+}$release in $10 \mathrm{~min}$ was $0.5 \times 10^{-6} \mathrm{M}$; the s.r.c. of FIL required to induce the s.r. of $\mathrm{K}^{+}$release in $6 \mathrm{~min}$ was $0.9 \times 10^{-5} \mathrm{M}$. These antibiotic concentrations were used in sterol-polyene mixtures. 0 , Ergosterol; $O$, cholesterol; $\boldsymbol{\Delta}$, zymosterol.

C. albicans. The concentration of antibiotic producing an increase in the rate of $\mathrm{K}^{+}$release of 2 to $3 \mathrm{nmol} / \mathrm{min} / \mathrm{mg}$ dry wt organism was determined and the effect of sterols on this rate then assessed either by adding sterol-antibiotic mixtures as described above or by adding the desired amount of sterol in ethanol solution to the electrode vessel immediately before adding the antibiotic solution. Results were the same whichever method of adding sterol was adopted.

Figure I shows the effect of increasing amounts of sterol on the time taken to attain a s.r. of $\mathrm{K}^{+}$release from $C$. albicans in the presence of a given concentration of AME (Fig. I $a$ ) or FIL (Fig. $\mathrm{I} b$ ). Zymosterol was included in the tests since this sterol is also a component of Candida plasma membranes (Marriott, 1975). In each case the time taken to reach s.r. increased in a linear manner with the increasing proportion of sterol. When AME was the antibiotic, zymosterol was the most effective antagonist while ergosterol was approximately twice as effective as cholesterol. The molar ratio of sterol to AME required to double the time taken to produce the standard response was $\mathrm{I} \cdot 6$ for zymosterol, $3 \cdot 0$ for ergosterol and $5 \cdot 2$ for cholesterol. When FIL was the antibiotic, cholesterol was a more effective antagonist than ergosterol; the molar ratio for doubling the response time for ergosterol was 0.24 , while cholesterol and zymosterol had similar activities at a molar ratio of 0.09 to 0.1 . In antagonism experiments of this nature, although the absolute values of the antagonistic ratios may vary from experiment to experiment, their relative values remain the same (Gale et al. 1975).

Freshly prepared suspensions of Mycoplasma have negligible leakage of $\mathrm{K}^{+}$, and Table I compares the effects of adding either AME or FIL, in the presence or absence of sterol, to organisms grown in the presence of cholesterol or ergosterol. The growth media and conditions were adjusted so that the total sterol content (cholesterol or ergosterol) of the membranes was approximately the same in both cases (Archer, 1975). The amount of $\mathrm{AME}$ required to release $\mathrm{K}^{+}$at a rate of 2 to $3 \mathrm{nmol} / \mathrm{min} / \mathrm{mg}$ dry wt organisms was much less for organisms grown in ergosterol than for those grown in cholesterol. The concentration of FIL required to produce this degree of leakage was greater for organisms grown in ergosterol than in cholesterol. 
Table I. Effect of cholesterol and ergosterol on the release of $K^{+}$from Mycoplasma mycoides subsp. capri in the presence of amphotericin methyl ester or filipin

Organisms grown in a modified Edward's 'medium containing either $0.08 \mathrm{~mm}$-cholesterol or $0.08 \mathrm{~mm}$-ergosterol as sole sterol. Organisms were harvested near the end of the exponential phase of growth, washed 3 times in $0.05 \mathrm{M}$-tris- $\mathrm{HCl}$ buffer $\mathrm{pH} \mathrm{8.0} \mathrm{containing} 0.125 \mathrm{M}$-sucrose, and suspended in the same medium at $0.5 \mathrm{mg}$ dry $\mathrm{wt} / \mathrm{ml}$ in an electrode vessel. $\mathrm{K}^{+}$release was followed with a $\mathrm{K}^{+}$-sensitive electrode (Archer, 1975; Gale, 1974)

\begin{tabular}{|c|c|c|c|c|c|c|c|c|}
\hline \multirow{2}{*}{$\begin{array}{l}\text { Antibiotic added } \\
\text { Sterol added }\end{array}$} & \multicolumn{4}{|c|}{$\mathrm{AME}^{*}$} & \multicolumn{4}{|c|}{ FIL $\dagger$} \\
\hline & \multicolumn{2}{|c|}{$\begin{array}{l}\text { Cholesterol } \\
\mathbf{K}^{+} \text {release }\end{array}$} & \multicolumn{2}{|c|}{$\begin{array}{l}\text { Ergosterol } \\
\mathbf{K}^{+} \text {release }\end{array}$} & \multicolumn{2}{|c|}{$\begin{array}{l}\text { Cholesterol } \\
\mathbf{K}^{+} \text {release }\end{array}$} & \multicolumn{2}{|c|}{$\begin{array}{l}\text { Ergosterol } \\
\mathrm{K}^{+} \text {release }\end{array}$} \\
\hline molar ratio & $\begin{array}{l}\mathrm{nmol} / \\
\mathrm{min} / \mathrm{mg}\end{array}$ & $\%$ & $\begin{array}{c}\mathrm{nmol} / \\
\mathrm{min} / \mathrm{mg}\end{array}$ & $\%$ & $\begin{array}{c}\mathrm{nmol} / \\
\mathrm{min} / \mathrm{mg}\end{array}$ & $\%$ & $\begin{array}{c}\mathrm{nmol} / \\
\mathrm{min} / \mathrm{mg}\end{array}$ & $\%$ \\
\hline $\begin{array}{l}\text { Organisms grown } \\
\text { in cholesterol }\end{array}$ & & & & & & & & \\
\hline 0 & $2 \cdot 20$ & 100 & $2 \cdot 20$ & 100 & $2 \cdot 38$ & 100 & $2 \cdot 38$ & 100 \\
\hline 0.5 & $\mathrm{I} \cdot 82$ & $82 \cdot 6$ & $I \cdot 54$ & 70 & $\mathrm{I} \cdot 54$ & 64.8 & $1 \cdot 92$ & $80 \cdot 5$ \\
\hline I & I 67 & $75 \cdot 8$ & $\mathrm{I} \cdot \mathrm{I} 4$ & $5 I \cdot 7$ & 0.94 & $39 \cdot 3$ & $1 \cdot 55$ & 65 \\
\hline 5 & $I \cdot 24$ & $56 \cdot 3$ & 0.86 & 39 & 0.51 & $2 I \cdot 4$ & $\mathbf{I} \cdot \mathbf{2 3}$ & $51 \cdot 8$ \\
\hline 10 & 0.81 & 36.8 & 0.38 & $17 \cdot 3$ & 0.31 & $12 \cdot 9$ & 1.06 & $44 \cdot 5$ \\
\hline $\begin{array}{l}\text { Organisms grown } \\
\text { in ergosterol }\end{array}$ & & & & & & & & \\
\hline 0 & $3 \cdot 32$ & 100 & $3 \cdot 32$ & 100 & $2 \cdot 49$ & 100 & $2 \cdot 49$ & 100 \\
\hline 0.5 & $3 \cdot 30$ & $99 \cdot 5$ & $2 \cdot 55$ & $76 \cdot 8$ & $2 \cdot 45$ & $98 \cdot 5$ & $2 \cdot 49$ & 100 \\
\hline I & $3 \cdot 15$ & $94 \cdot 8$ & $2 \cdot 30$ & $69 \cdot 3$ & $2 \cdot 30$ & $92 \cdot 5$ & $2 \cdot 45$ & $98 \cdot 5$ \\
\hline 5 & 2.89 & 87.0 & $2 \cdot 14$ & $64 \cdot 4$ & 2.08 & $83 \cdot 4$ & $2 \cdot 34$ & 94 \\
\hline 10 & $2 \cdot 38$ & $7 I \cdot 9$ & $\mathrm{I} \cdot 87$ & $56 \cdot 4$ & $I \cdot 29$ & $51 \cdot 8$ & 2.05 & 82.6 \\
\hline
\end{tabular}

* AME added at $5 \mu \mathrm{M}$ for organisms grown in cholesterol, and $0.5 \mu \mathrm{M}$ for organisms grown in ergosterol.

$\dagger$ FIL added at 10 $\mu \mathrm{M}$ for organisms grown in cholesterol, and $20 \mu \mathrm{M}$ for organisms grown in ergosterol.

Table I also shows the antagonistic effects of cholesterol and ergosterol against the antibiotics. When tested against Mycoplasma grown in cholesterol, the molar ratios of sterol to polyene required to reduce the effect of the antibiotic by $50 \%$ were $\mathrm{I} \cdot 5$ for ergosterol and 6.5 for cholesterol against AME, or 6.3 for ergosterol and 0.7 for cholesterol against FIL. Antagonism was not so marked in tests using organisms grown in ergosterol, but it can again be seen that ergosterol was a more effective antagonist than cholesterol against AME while the reverse was true against FIL.

The conclusions that can be drawn from these and previous results are that AME is more toxic to organisms whose main membrane sterol is ergosterol than to those containing cholesterol, and that ergosterol is a more effective antagonist than cholesterol to AME but a less effective antagonist than cholesterol to FIL. Since the mode of action in vivo of these polyenes is believed to arise from the formation of hydrophobic complexes between polyene molecules and sterols (De Kruijff \& Demel, 1974) it would appear that AME has a higher affinity for ergosterol than for cholesterol while FIL has a higher affinity for cholesterol than ergosterol. The selective toxicities of these two antibiotics can therefore be attributed to these differences in affinity.

We thank Dr C. P. Schaffner, Rutgers University, for a gift of AME, and Dr G. Whitfield, Upjohn Co., Kalamazoo, U.S.A. for a gift of FIL ( $75 \%$ pure). We are grateful to the Medical Research Council for a grant to cover the expenses of this work, which was carried out during the tenure of a M.R.C. Studentship by D.B.A. 


\section{REFERENCES}

ARChER, D. B. (1975). Modification of the membrane composition of Mycoplasma mycoides subsp. capri by the growth medium. Journal of General Microbiology 88, 329-338.

De KRUIJfF, B. \& Demel, R. A. (I974). Polyene antibiotic-sterol interactions in membranes of Acholeplasma laidlawii cells and lecithin liposomes. III. Molecular structure of the polyene antibiotic-cholesterol complexes. Biochimica et biophysica acta 339, 57-70.

GaLE, E. F. (1973). Perspectives in chemotherapy. British Medical Journal 4, 33-38.

GALE, E. F. (1974). The release of potassium ions from Candida albicans in the presence of polyene antibiotics. Journal of General Microbiology 80, 45I-465.

Gale, E. F., Johnson, A. M., KerRidge, D. \& KoH, T. Y. (1975). Factors affecting the changes in amphotericin sensitivity of Candida albicans during growth. Journal of General Microbiology 87, 20-36.

MARRIOTT, M. S. (1975). Isolation and chemical characterization of plasma membranes from the yeast and mycelial forms of Candida albicans. Journal of General Microbiology 86, I I5-132.

Nozawa, Y., Kitajma, Y., SekiYat, T. \& Ito, Y. (1974). Ultrastructural alterations induced by amphotericin B in the plasma membrane of Epidermophyton floccosum as revealed by freeze-etch electron microscopy. Biochimica et biophysica acta 367, 32-38.

Verleij, A. J., De KruijfF, B., Gerritsen, W. F., Demel, R. A., van Deenen, L. L. M. \& Ververgaert, P. H. J. (1973). Freeze etch electron microscopy of erythrocytes, Acholeplasma laidlawii cells and liposomal membranes after the action of filipin and amphotericin. Biochemica et biophysica acta 29r, 577-581. 